\title{
New Concept of Visual Communication Design in the Digital Age
}

\author{
Wei Xiao \\ Wuchang Shouyi University, Wuhan, Hubei, 430064
}

Keywords: visual communication; digital age; new concept

\begin{abstract}
With the continuous development of modern social science and technology, in the digital era, many industries and fields are undergoing dramatic changes. In the information era, digitization has become an important part of people's work and life and a new trend of development, which is also the case for modern industries. In the digital age, the expressive power of visual transmission design has been greatly improved, and the overall visual performance design has also been more visualized.
\end{abstract}

\section{Introduction}

At the end of the 20th century, with the rapid development of computer technology and networks, humans experienced the third technological revolution in history. From the industrial society to the digital information society, digital products have become necessities and chases for everyday life, and digital information dissemination has become the major There is no doubt that people have entered the era of "digital survival". Digital information dissemination has not only changed people's way of life, but also deeply influenced people's thinking. The advancement of science and technology has led to the emergence of new forms of art. The development of digital technology has changed the working model of art design, resulting in a new design concept and expanding the extension of design. Visual communication design is an important part of contemporary art design. It is an integrated discipline integrating art and science and technology. It is inevitably influenced and impacted by the digital age. The development of technology brings new opportunities for development and promotes design concepts to Change of thinking. Today, the visual expression of communication design has been extended from two-dimensional planes to three-dimensional and four-dimensional. The mode of communication has evolved from one-way passive transmission to interactive information exchange, and presentation vectors have also evolved from print media to digital media. The digital age has provided a new design language for visual communication design. At the same time, it also impacts traditional design patterns and concepts. Therefore, it must be constantly improved and integrated in the reform to seek expressions that are more in line with the needs of the times. The purpose of visual communication design is to use aesthetic methods to realize the effective transmission of information. With the change of information transmission mode in the new era, digital technology and media platforms provide a new exhibition space and design means for design, and the category of visual communication design. Extending to almost all media fields, the design language was reconstructed, and the original ideas of thought needed to be broken and changed. Under the digital media environment, the entire social landscape has undergone great changes [1]. As the visual communication design at the frontier of information transfer, it is necessary to create works that meet the needs of the times and adapt to the new modes of communication. The development of media technology has had a huge impact on the teaching mode and design of traditional visual communication design. This is an indisputable fact. Faced with this situation, we should think about how we can better integrate technology and art, use advanced technology to deliver more accurate and effective information services, and in the process of research, designers can be viewed from a dynamic perspective. The use of design forms to achieve effective delivery of information. 


\section{Characteristics of Visual Communication Design in Digital Media}

From a functional point of view, the extension of visual communication design to digital media is the development trend of the information age. Whether it is traditional graphic design or dynamic visual design, multimedia design, and interface design, they are all aimed at information transmission and aesthetics. The basic visual elements are the same. The design of visual communication in digital media is mainly through the interface as the carrier for information presentation. Its external form of expression is screen and computer. Traditional printing design is based on paper, and the interaction, multimedia, and digital media are not considered temporarily. The auditory elements and digital interface are the digital representation of graphic design. Information is transformed into visual. The audience is still in front of the audience. It is the combination of visual design elements such as graphics, text, and color. Changes and Unity, Rhythm and Rhythm, Comparison and Equilibrium, Repetition The compositional laws and form rules such as radiation, deconstruction and the like apply equally to the visual communication in digital media [2].

Visual communication design is an activity that conveys information through visual symbols. It not only includes the production of design information, but also includes the dissemination of information. Visual communication design is a visual communication process. In the digital age, digital technology and digital media have gone deep into people's daily lives, changing the way people accept information. In the digital information dissemination today, the integration of media technology, computer technology and visual design has not only changed the language form of visual communication design, but also changed the way of information transmission, from the static stereo display to the three-dimensional, dynamic development, one-way communication in the direction of passive interaction and humanity.

With the change of the visual communication design carrier, the audience's cognitive psychology of the visual language will also change. In digital media communications, the audience's cognitive psychology is the basis for visual communication design. Cognitive psychology considers that the cognitive process of human beings is the process of accepting, encoding, storing, exchanging, operating, retrieving, extracting, and using information. The human mental activity is the information processing system, information collected by the senses, after analysis, Stored, converted, and then used, these activities are called information processing. In digital media communication, the forms of expression and acceptance of visual communication design are very different from those of traditional media, and thus affect the cognitive psychology of the audience.

\section{New Concepts of Visual Communication Design}

Humanized design is the core content of the entire visual transmission design, and it is also a core concept of design. In the continuous development of modern digital technology, the design itself has also realized further development on the basis of basic functions, and has paid more attention to the pursuit of the nature of human nature, and even more focused on the feelings and experiences of people themselves, and paid attention to the needs of the humanities. Visual communication itself pays attention to people's own concerns, starting from many aspects such as mentality, habits, etc. Only designs that can fully satisfy people's needs can be outstanding designs, and can be based on the digital era and realize the development needs of visual communication design in the new era. Although visual communication itself is a form of external performance, in the process of continuous development, this design also incorporates more connotations, and it also realizes the further development and innovation of traditional design concepts, and allows In the process of watching the audience, it is easier to experience the connotation of the work itself and improve the emotional experience. In the design, the humanized design concept is also reflected in the overall design security, how to combine the visual needs of people, highlight the design, and better adapt the senses of the people. It is also necessary for designers to explore further [3].

In the process of development, visual communication design will also better conform to the 
theme of time generation and realize innovation and change with the times. In modern society, innovation is an important force and impetus, and it is very important for the development of various industries. In the digital age, visual communication design itself also incorporates more contemporary elements in its development. In the idea innovation, we must bravely integrate more new thinking methods and elements, and through continuous exploration and development, let the visual design products exhibit more time-representative characteristics. In visual communication design, designers themselves must also have a strong sense of learning and learning ability. They should constantly explore during the development of the times, constantly break through limitations and limitations, and constantly introduce new ideas. Only in this way can we stand at the forefront of the times in order to design. Outstanding works. As regards the visual transmission design, the excellent work itself not only has a strong artistic style, but also has a great influence on the values and attitudes of the recipients themselves, and will have a certain degree of impact on the behavior. In the process of designing, the designers should also pay attention to this aspect of the problem, to make a more comprehensive consideration of the design concept, and better fit and integrate into the elements of the era [4].

In the process of continuous development in the new era, digital technology has continued to evolve and mature. In visual communication design, the development of design concepts must also emphasize the application of technology. In the design, through the effective application of digital technology, to further enhance the artistic effect, so that the entire design can better overcome the limitations of the traditional design model, so that the efficiency of the design can be better improved, so that the entire design can be given to the audience Better visual enjoyment improves the overall visual impact. The development of new technologies also brings new exploration space. Digital communication design is developing. It should be better applied to new media. Through the combination of multiple tools, the sensory experience in all aspects can be better integrated. . Development should focus on the embodiment of technology, and be good at using various new technologies, so that the needs of the entire visual design can be better satisfied, so that the entire artistic expression can achieve better results. In the situation where the technology develops to a certain level, the concept of visual communication design will also need to integrate different technical forms and carry out a further exploration to explore more and newer styles and forms. The development of technology is a new opportunity for the visual transmission design. In the digital age, more attention should be paid to the technical level.

In the digital era, visual communication design has undergone great changes in its own form, and the appearance of many new carriers, new forms, and new materials has enabled many previously unviable ideas to be visualized, allowing many theoretical ideas. It has been achieved and has given a broader space for visual communication design. In the digital age, in visual communication design, it is necessary to better realize the diversified needs, diversify the contents and forms of the exhibition, and make the psychological activities and visual feelings of the attention activities more satisfying. Visual communication design. The development and application of digital technology has enabled the overall advancement and drive of graphic design technology. The production process of the entire art design work has also undergone great changes, and multimedia technology has further deepened the information of sound, graph and text [5]. The integration of the entire work itself has gained a deeper spread of space, more powerful communication power and more imaginative spreading imagination. In past advertising designs, paper advertisements were the main design choices, and the form of posters was generally adopted. In the digital era, the devices of visual transmission design were more abundant, and television advertisements and other forms emerged, which promoted the dissemination of information. The visual communication design in the background of digital age adopts a combination of computers and flexible design of visual images, giving viewers a kind of surreal visual effects, enriching the artistic means of visual communication design, expanding people's thinking, and inspiring designers' inspiration. Won the audience's favor, presented to the audience with various forms of artistic techniques. 


\section{Conclusion}

This article mainly studies how the visual communication design in the era of digital information dissemination can realize the innovation of the design form. According to the new characteristics brought by the digital media, the information transmission is more efficient and humanized. In the face of the information revolution, digital media with computers and network technologies as the core is increasingly becoming the mainstream form of information dissemination, and visual communication design is used as a medium for visual information transmission. In the new media environment, its design fields and extensions of expressions are all Was extended. This article attempts to study the visual communication design language from the design form, and proposes the future development trend of visual communication design.

\section{References}

[1] He Zhong. Visual Communication Art Design in the New Media Era: On the Influence of New Media Art on Visual Communication Design Art [J]. Art Grand View. 2009 (07)

[2] Fan Yuanyuan. Contemporary Visual Communication Design: The Value and Significance of Interactivity [J]. Packaging World. 2010 (05)

[3] Tan Xuhong. When New Media Art and Visual Communication Design [J]. Literary Review. 2010 (04)

[4] Shang Xiaoming. The New Context of Visual Communication Design in the Information Age [J]. Packaging Engineering. 2009 (11)

[5] Wu Qiao. Dynamic Design - Visual Communication under New Media Conditions [J]. Digital Fashion (New Visual Art). 2009 (04) 